\title{
Homeotic transformations and limb defects in Hox A11 mutant mice
}

\author{
Kersten M. Small and S. Steven Potter ${ }^{1}$ \\ Division of Basic Science Research, Children's Hospital Research Foundation, Cincinnati, Ohio 45229 USA
}

\begin{abstract}
Hox $A 11$ is one of the expanded set of vertebrate homeo box (Hox) genes with similarities to the Drosophila homeotic gene, Abdominal-B $(A b d-B)$. These $A b d-B$-type Hox genes have been shown to be expressed in the most caudal regions of the developing vertebrate embryo and in overlapping domains within the developing limbs, suggesting that these genes play important roles in pattern formation in both appendicular and axial regions of the body. In this report whole-mount in situ hybridization in mouse embryos gave a precise description of $\mathrm{Hox} A 11$ gene expression in the developing limbs and in the axial domain of the developing body. In addition, we generated a targeted mutation in Hox A11 and characterized the resulting phenotype to begin to dissect developmental functions of the $A b d-B$ subfamily of $H o x$ genes. Hox $A 11$ mutant mice exhibited double homeotic transformations, with the thirteenth thoracic segment posteriorized to form an additional first lumbar vertebra and with the sacral region anteriorized, generating yet another lumbar segment. Furthermore, skeletal malformations were observed in both forelimbs and hindlimbs. In mutant forelimbs, the ulna and radius were misshapen, the pisiform and triangular carpal bones were fused, and abnormal sesamoid bone development occurred. In mutant hindlimbs the tibia and fibula were joined incorrectly and malformed at their distal ends. Also, an enlarged sesamoid developed ventral to the tibiale bone. Both heterozygous and homozygous mice displayed mutant phenotypes adding an additional level of complexity to the Hox code hypothesis.
\end{abstract}

[Key Words: Hox A11; mouse; development; homoetic transformation; limb defects]

Received July 12, 1993; revised version accepted September 29, 1993.

The genetic program of pattern formation during vertebrate development is only beginning to be deciphered. In Drosophila, however, it has been clear for some time that transcription factor genes carrying the homeo box sequence are among the master switch regulators of development, capable of initiating genetic cascades that control the developmental destinies of groups of cells (Gehring 1987). Striking similarities in sequence, organization and expression patterns between Drosophila and vertebrate homeo box (Hox) genes originally suggested important developmental functions for the vertebrate counterparts (Graham et al, 1989). This view was supported further by transgenic fly and transgenic mouse experiments in which mammalian $H o x$ genes were introduced into flies and vice versa (McGinnis et al. 1990; Malicki et al. 1990, 1992; and Awgulewitsch and Jacobs 1992). Significant conservation of cis-regulatory element and coding sequence functions were observed, despite the rather large evolutionary separation. Moreover, recent studies of mice carrying misexpression or null mutations of Hox genes have found structure deletions and homeotic transformations similar to those seen previously in flies, demonstrating further the importance of these genes in mammalian development (Kessel et al.

'Corresponding author.
1990; Chisaka and Cappechi 1991; Lufkin et al. 1991, 1992; Chisaka et al. 1992; Kaur et al. 1992; LeMouellic et al. 1992; McLain et al. 1992; Ramirez-Solis et al. 1993).

The potential roles of Hox genes in limb development are of particular interest. Limb formation has served as an excellent model system for pattern generation in vertebrates. The morphogenetic principles of limb formation are well conserved, in that grafted pieces of limb buds from mammals or reptiles are capable of driving appropriate chicken limb development (Fallon and Crosby 1977). At the posterior edge of the limb bud resides the zone of polarizing activity (ZPA), which appears to be the source of a morphogen gradient important in establishing anteroposterior polarity (Tickle et al. 1975). Moreover, the outgrowth of the limb bud is controlled by the apical ectodermal ridge (AER), a specialized ectodermal structure along the rim of the distal tip of the limb bud. The AER apparently signals the group of mesenchymal cells beneath it, the progress zone, where pattern specification of limb cells is determined (Summerbell et al. 1973). In addition, the Turing reactiondiffusion process has been proposed as a mechanism for the generation of standing waves of certain morphogens in the developing limb (Turing 1952).

A number of murine $H o x$ genes of the $A b d-B$ subfam- 
ily have been shown to be expressed during limb development, suggesting that they play an important role in limb morphogenesis. Interestingly, the 5' ends of the vertebrate Hox clusters have been expanded considerably when compared with Drosophila. The most $5^{\prime}$ gene in the Drosophila cluster is $A b d-B$, whereas the vertebrate clusters have a total of 15 genes that are either direct homologs of $A b d-B$ or are located even more 5'. Each of the 15 genes carries sequence characteristics that mark it as a member of the $A b d-B$ subfamily. In mammals, therefore, a striking $40 \%$ of all Hox genes are of the $A b d-B$ group; and for most of these genes, expression in the developing limb has now been shown. The Hox D9, $D 10, D 11, D 12$, and $D 13$ genes, for example, establish an anterior-to-posterior gradient (Dolle and Duboule 1989; Dolle et al. 1989,1991; Nohno et al. 1991), Hox C10 is expressed in an antero-proximal region (Peterson et al. 1992), and there is evidence that the Hox A10, A11, and $A 13$ genes are expressed in proximodistal-restricted domains in developing chick and mouse limbs (Yocouchi et al. 1991; Haack and Gruss 1993).

To begin to understand the developmental functions of the $A b d-B$ subfamily genes we have examined the expression pattern of the Hox A11 gene during mouse embryogenesis using whole-mount in situ hybridization. Furthermore, we have generated a targeted mutation in Hox $A 11$ and characterized the resulting phenotype. Interestingly, Hox A11 mutant mice develop with skeletal malformations in both forelimbs and hindlimbs. In the trunk we observed a double homeotic transformation, with one vertebral segment posteriorized and others apparently anteriorized. Moreover, mutant effects were observed in both heterozygous and homozygous animals.

\section{Results}

\section{Expression of Hox All}

We originally cloned the Hox A11 gene using a degenerate oligonucleotide probe carrying a combination of sequences capable of encoding the most conserved KIWFQNRR amino acid sequence region of the homeo domain (Singh et al. 1991). Sequence analysis and chromosomal mapping allowed this gene to be identified as Hox-1.9, which is now Hox A11 under the new system of nomenclature (Scott 1992).

The Hox A11 expression pattern during embryogenesis has been examined previously in both mice and chickens using traditional in situ hybridization procedures (Yocouchi et al. 1991; Haack and Gruss 1993). Nevertheless, to generate a more precise three-dimensional picture of the transcription pattern of this gene in developing limbs, and to determine the rostral-caudal boundary of expression in the mesoderm of the body, which has not been described previously, whole-mount in situ hybridizations were performed. A segment of $\sim 300$ bp located immediately $3^{\prime}$ of the homeo box was made by PCR and subcloned into pBS (KS) for preparation of sense and antisense riboprobes.

At embryonic day 8.5 (E 8.5 ) there was very little $H o x$ A11 expression, although a faint hybridization signal was reproducibly observed in a caudal-lateral region of the body, as shown in Figure 1A. One day later, however, at E9.5, Hox A11 was transcribed extensively in the four developing limb buds and in the caudal portion of the body posterior to the hindlimbs. At this time there was a gradient of expression in the limb buds, with the distal regions showing the highest abundance of Hox A11 tran-



Figure 1. Expression pattern of Hox A11. Whole-mount in situ hybridizations were used to determine expression at E8.5 (A), E10.5 $(B)$, E9.5 $(C)$, and E10.75 $(D)$. The arrowhead in $A$ marks the weak but reproducible hybridization signal observed on the most caudal portion of the tail. The arrowhead in $C$ marks the intense hybridization of the developing hindlimb. The brain ventricles were perforated to reduce antibody trapping and resulting false signal. 
scripts. Although not apparent in Figure 1C, we also observed a separate region of expression at the base of the limbs, as described previously (Haack and Gruss 1993). Expression in the trunk at E9.5 extended posteriorly to the tip of the tail, with a diffuse anterior boundary. In Figure $1 \mathrm{C}$ this anterior boundary coincided roughly with the mid-region of the hindlimb; but in other embryos, presumably representing slightly different times of gestation, there was a faint indication of expression as far anterior as the rostral edge of the hindlimb bud.

By day E10.5 the Hox A11 expression in the torso was much reduced, and expression in the forelimbs was now restricted to the most distal region (Fig. 1B). At E10.75 the expression in the body was not detectable above background, and the continued outgrowth of the limb buds had produced a ringed pattern of Hox A11 expression, with the most distal regions devoid of transcripts. As shown in Figure 1D, however, this proximodistalrestricted expression was not symmetric about the circumference. In the hindlimb, for example, the anterior edge of the expression domain was considerably more distal than the posterior edge. Likewise, the levels of expression were not uniform, with the anterior portion of the hindlimb having higher levels of Hox A11 transcripts. It should also be noted that during this E9.5E10.75 period of development, Hox $A 11$ expression was apparent on both the dorsal and ventral surfaces of developing limbs. All other apparent signals in Figure 1, such as the otic vesicles and brain ventricles, were the result of antibody trapping and are also seen with sense strand probes used as controls.

\section{Targeted disruption of Hox All}

The replacement construct, $p G K O H o x$ A11-129, was used for targeted disruption of the Hox $A 11$ gene; it included $10 \mathrm{~kb}$ of homologous $129 / \mathrm{Sv}$ genomic DNA and deleted a $2.7-\mathrm{kb}$ region containing the $3^{\prime}$ portion of the Hox A11 gene, including the homeo box (Fig. 2A). $p G K O H o x$ A11-129 was electroporated into D3 embryonic stem (ES) cells (Doetschman et al. 1985), and $\sim 300$ G418 and gancyclovir-resistant colonies were analyzed by Southern blot hybridization using a DNA probe from a region flanking the replacement construct (Fig. 2). One clone $(20)$ gave the predicted patterns of hybridization for homologous recombination when ES cellular DNA was digested with BstXI, NcoI, or SpeI. Hybridization with a neo probe further confirmed that clone 20 was targeted (data not shown). Clone 20 ES cells were injected into $\mathrm{C} 57 \mathrm{Bl} / 6 \mathrm{~J}$ blastocysts, and 10 male germ-line chimeras were generated.

Mice heterozygous for a disruption in Hox A11 were interbred to generate homozygotes. Figure $2 \mathrm{~B}$ shows a Southern blot genotyping of the resulting wild-type, heterozygous, and homozygous mutant mice. The progeny of $\operatorname{Hox} A 11$ heterozygous matings, were genotyped, identifying 43 wild-type, 84 heterozygous, and 45 homozygous mice, which closely approximates the predicted Mendelian ratio. Homozygous mice were viable, and careful dissections detected no alterations in soft tissues.
External morphology and behavior were indistinguishable between the targeted mice and their wild-type littermates.

\section{Skeletal analysis of Hox A11 mutant mice}

Interestingly, skeletal staining revealed malformations of both axial and appendicular skeletal elements in both heterozygous and homozygous mutant mice. Figure 3 illustrates the axial skeletons of one wild-type, two heterozygous, and two homozygous mutant mice. In both homozygotes the thirteenth thoracic vertebra (T13) was converted to the first lumbar vertebra (L1) with no attached ribs. In most homozygotes, this transformation was complete, resulting in the total absence of the thirteenth pair of ribs (Fig. 3I), but in some cases distal cartilaginous remnants of ribs were observed (Fig. 3J). Somewhat surprisingly, this transformation was also seen in heterozygotes, although generally in an incomplete form, with significant portions of the ribs remaining. The proximal and distal elements of the ribs were most resistant to the mutation effects, as these components often remained in heterozygotes, with the central rib regions absent (Fig. 3G). The observed T13-to-L1 transformation appeared to be near the anterior boundary of the observed expression domain of the Hox A11 gene. It is important to note that although the thirteenth thoracic segment was converted to a first lumbar segment, the twelfth thoracic vertebra retained its normal identity, as determined by rib morphology. There was no apparent posteriorization of any other thoracic vertebrae.

The skeletons of the Hox A11 mutants also displayed a second homeotic transformation at the lumbosacral transition. This was evidenced by the presence of two extra lumbar vertebrae in many of the Hox A11 mutant mice. As shown in Figure 3 and summarized in Table 1, six lumbar segments were generally observed in wildtype mice, although occasionally we saw five (a normal wild-type variant). In mutants, seven lumbar segments were often counted, the result of conversion of a thoracic to a lumbar; but about half of the mutants actually have yet another additional lumbar segment, or eight total. One explanation is an anteriorization of sacral segments generating an additional lumbar segment. We cannot exclude, however, an alternate model, stating that the mutation simply resulted in the formation of an extra lumbar vertebra, with no homeotic transformation of sacral segments. The net results of these two models are very similar and experimentally indistinguishable, as the tails of wild-type mice have variable numbers of vertebrae. It is therefore impossible to make meaningful comparisons of total numbers of vertebrae.

In addition to the vertebral transformations, two homozygous mutants displayed malformations in which one of the the second ribs was fused inappropriately at the sternum. In one mutant, the second rib was fused to the first rib near the sternum (Fig. 4B), and in the other mutant, the second rib was fused caudal to its normal position causing misalignment of the remaining ribs $(\mathrm{r} 3$ r) and abnormal sternal segmentation along the length 

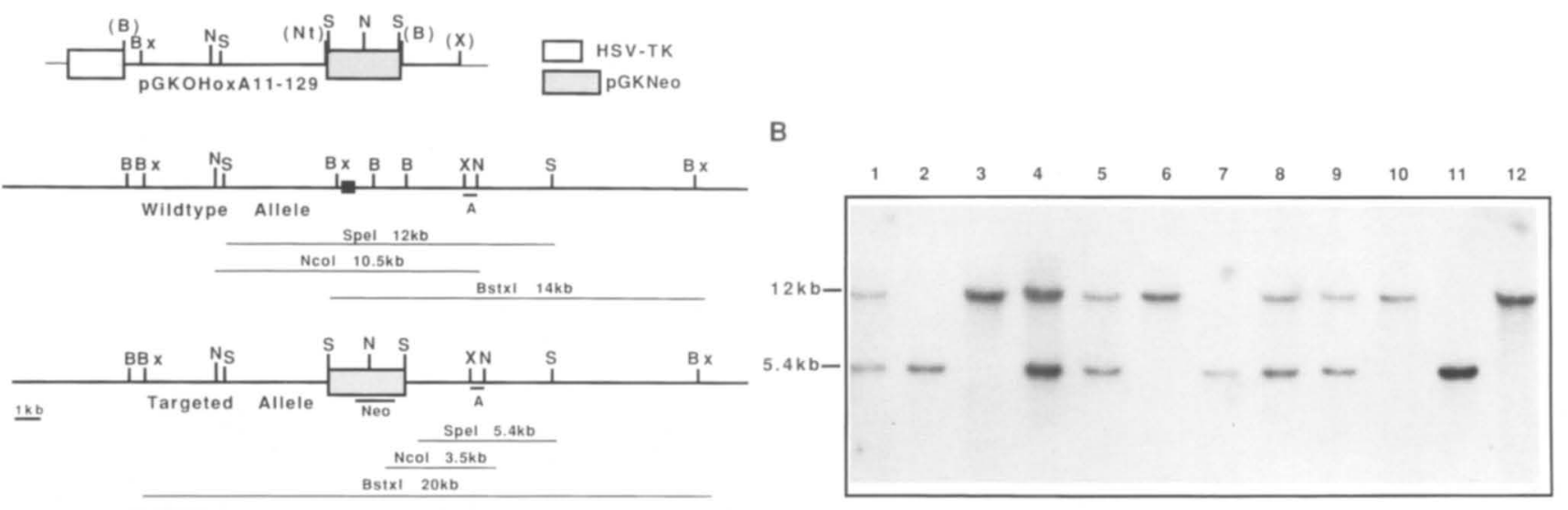

Figure 2. The Hox $A 11$ gene targeting vector, wild-type allele, targeted allele, and mouse genotype analysis. (A) Structure of the replacement targeting vector, $p G K O H o x A 11-129$, used to disrupt the Hox A11 gene in ES cells. BamHI (B), NotI (Nt), and XbaI (X) sites were eliminated (in parentheses) when 7.5-kb BamHI-NotI and 2.5-kb BamHI-XbaI fragments were subcloned, 5' and 3', respectively, of the $p G K N e o$ cassette. Construction of $p G K O H o x$ A11-129 deleted a 2.7-kb region that included the Hox A11 homeo box. $(A)$ Diagram of the wild-type and targeted SpeI $\langle\mathrm{S}|, N$ coI $(\mathrm{N})$, and $B s t \mathrm{XI}(\mathrm{Bx})$ fragments that hybridized to probe A, a $350-\mathrm{bp}$ $X$ baI-NcoI-flanking DNA fragment, not present in the targeting vector. (B) Genotyping of 12 littermates from a Hox $A 11+/-$ intercross. DNA was digested with SpeI, with a 12 -kb band of hybridization indicating a wild-type allele and a 5.4-kb band indicating a targeted allele. Littermates that are wild type (lanes 3,6,10,12), heterozygous (lanes 1,4,5,8,9), and homozygous for a disruption in $H o x$ A11 (lanes 2,6,11) are shown. (HSV-TK) The herpes simplex thymidine kinase gene cassette (Mansour et al. 1988); (pGKNeo) the neomycin resistance gene cassette (Soriano et al. 1991). (ロ) The Hox A11 homeo box.

of the sternum (data not shown). These malformations were unexpected because they appeared anterior to the observed expression domain of $\operatorname{Hox} A 11$.

The targeted ablation of the Hox A11 gene described in this report directly alters the Hox code expression pattern during limb development; and, as a result, malformations were observed in both forelimbs and hindlimbs of Hox A11 mutant mice. Initial analysis of newborn skeletons showed a malformation of two carpal bones in mutant forelimbs. The pisiform and the triangular were fused together in mutants to form a single bone. As shown in Figure 5A, there was usually complete fusion of these two bones along their entire contiguous lengths. This formation of one bone from what would normally be two also results in a subtle spacing difference of the other carpal bones in the mutants. As summarized in Table 1, there was some variability in this phenotype, with 19 of 23 homozygous mutant forelimbs showing complete fusion but 2 forelimbs showing only partial fusion and 2 forelimbs appearing normal. While all of the wild-type and 34 of the heterozygote forelimbs were normal, 7 of the heterozygote forelimbs showed partial fusion and 10 had complete fusion. There was no apparent correlation in individuals between the severities of the axial and forelimb malformations.

Analysis of adult mutant skeletons revealed additional forelimb malformations not evident in newborn skeletons. In the adult, the pisiform is not only fused to the triangular but is distinctly altered in shape, as shown in Figure 5, B and C. The distal end of the ulna, the ulnar epiphysis, was more rounded in shape in mutants than in wild types (Fig. 5B), and mutant radius and ulna bones appeared wider along their entire lengths as compared with wild type (Fig 5C). In addition, in all homozygotes examined, abnormal sesamoid bone development occurred near the distal-medial side of the radius (Fig. 5C). This sesamoid bone was only observed in 1 of 10 wildtype forelimbs analyzed and was much smaller in size. In heterozygous mutants this sesamoid was present and intermediate in size.

Adult Hox A11 mutant skeletons also revealed several hindlimb defects. As shown in Figure 6A, the fibula of homozygous mutant mice joined with the tibia at a position distal to that observed in wild-type hindlimbs. In most homozygous mutants analyzed, the fibula failed to fuse completely with the tibia, as evidenced by a small gap between the two bones. In heterozygotes these bones attached at an intermediate position. Also in mutant hindlimbs, the distal ends of the tibia and fibula, the medial malleolus and the lateral malleolus, were severely malformed, lacking the contours normally seen in wild-type bones; and similar to what was observed in the radius and ulna of mutant forelimbs, both the mutant tibia and fibula appeared wider as compared with wild type (Fig. 6A-C). In addition, the sesamoid located ventral to the tibiale bone appeared larger in size in both heterozygotes and homozygotes (Fig. 6B,C).

\section{Discussion}

\section{Expression pattern}

In this report we describe the Hox A11 expression pattern and mutant phenotype. The use of whole-mount in 


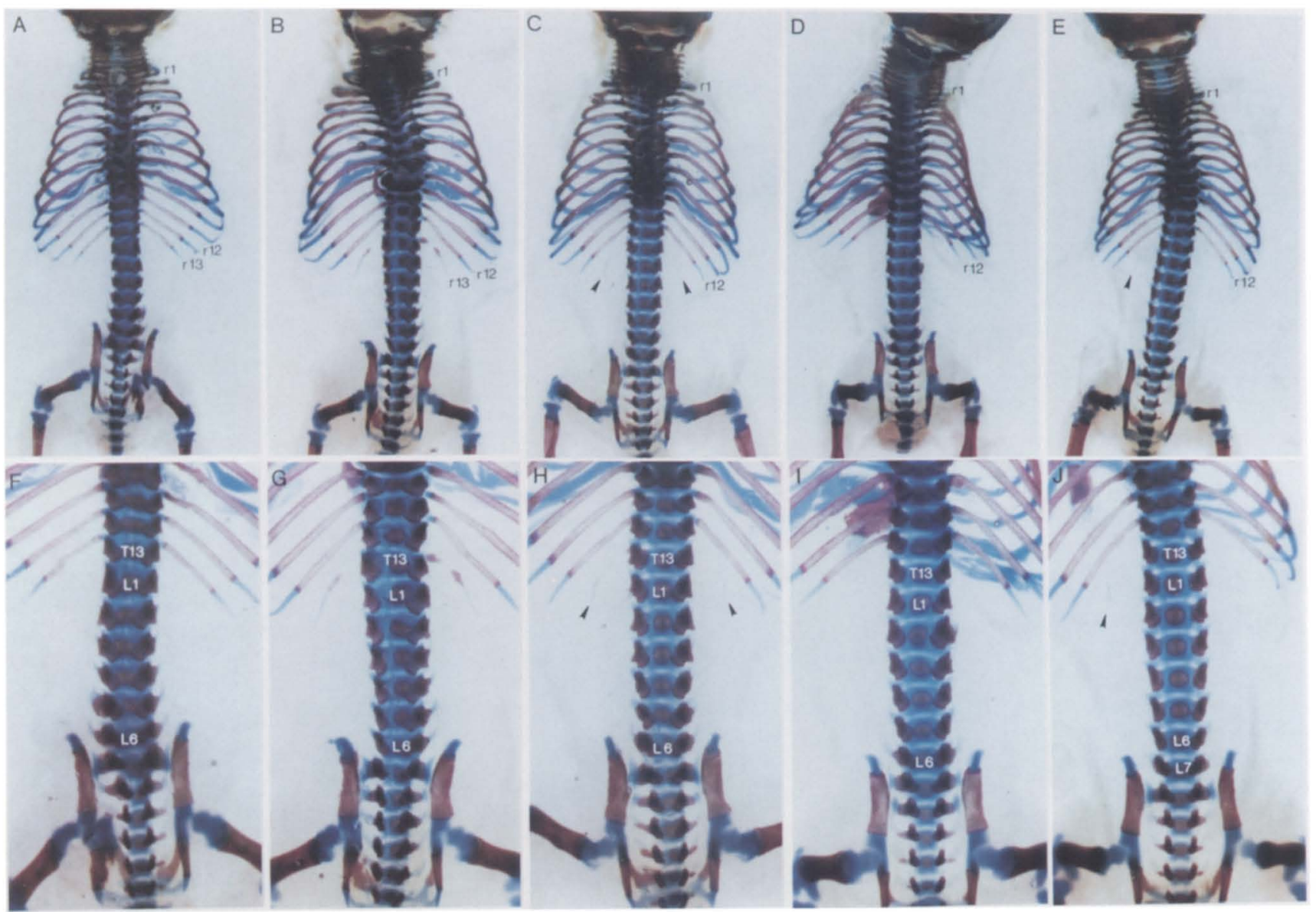

Figure 3. Comparison of skeletons from $\operatorname{Hox} A 11+/+\langle A, F), \operatorname{Hox} A 11+/-(B, C, G, H)$, and $\operatorname{Hox} A 11-/-(D, E, I, J)$ mice. $(A)$ Dorsal view of ribs and vertebrae of a $H o x A 11+/+$ skeleton. (r1) The first rib pair that is attached to the first thoracic vertebra; $(\mathrm{r} 12$ and $\mathrm{r} 13)$ the twelfth and thirteenth pair of ribs attached to the twelfth and thirteenth thoracic vertebrae, respectively. $(F)$ Close-up view of the same skeleton; (T13) the thirteenth thoracic vertebra; (L1 and L6) the first and sixth lumbar vertebrae, respectively. $(B)$ Partial development of the thirteenth pair of ribs in a Hox $A 11+/-$ skeleton. $(G)$ Close-up view of $B$. (C) Hox $A 11+/-$ skeleton with rudimentary thirteenth ribs indicated by arrowheads. $(H)$ Close-up view, showing the transformation of T13 to L1. For reference, the vertebra that would normally be T13 is labeled as such even though it is transformed into L1. $(D)$ Complete absence of the thirteenth pair of ribs in a Hox $A 11-/-$ skeleton. (I) Close-up view of $D$ showing transformation of T13 to L1. $(E)$ A single rudimentary rib located near T13, indicating the transformation of T13 to L1. (/) The development of an additional lumbar vertebra, L7. This - / skeleton has 12 pairs of ribs and a total of 8 lumbar vertebrae.

situ hybridizations allowed a precise description of $H o x$ A11 expression in developing limbs and defined the axial domain of expression in the developing body. Early. forming limb buds, at E9.5, showed widespread expression. But later, as paddle structures were generated, there was a gradient of expression with proximal regions of the limbs apparently devoid of Hox A11 transcripts and with the distal tips showing the greatest hybridization signals. By E10.75, however, continued limb outgrowth had produced a proximodistal-restricted band of expression. This ring of expression included both dorsal and ventral sides of the developing limbs but was uneven about the circumference in terms of both proximo-distal location and level of expression.

In the embryo body, Hox A11 expression was observed in only the most caudal region, as might be predicted based on its $5^{\prime}$ location in the Hox $A$ cluster of genes. Expression was transient, with peak levels seen at E9.5E10.0. During this period there was some fluctuation in the diffuse anterior boundary of expression, with a distinct hybridization signal detected as far rostral as the anterior edge of the hindlimb bud, which corresponds to prevertebrae 19 (T12) and 20 (T13) (Holland and Hogan 1988).

\section{Mutant phenotype}

Mice heterozygous and homozygous for a mutation in the Hox A11 gene showed homeotic transformations of the thirteenth thoracic vertebra to the first lumbar vertebra. In heterozygotes, this transformation was often incomplete, and occurred in $\sim 50 \%$ of the mice. In ho- 
Table 1. Newborn skeleton morphology according to Hox A11 genotype

\begin{tabular}{|c|c|c|c|}
\hline Morphology & ++ & $+1-$ & $-1-$ \\
\hline \multicolumn{4}{|l|}{ Rib and vertebrae transformations } \\
\hline 13 ribs (normal) & 25 & 22 & 0 \\
\hline \multicolumn{4}{|l|}{6 lumbar vertebrae ${ }^{a}$} \\
\hline \multicolumn{4}{|l|}{12 ribs with partial thirteenth } \\
\hline $\operatorname{rib}(s)$ & 0 & 15 & 0 \\
\hline \multicolumn{4}{|l|}{6 lumbar vertebrae } \\
\hline \multicolumn{4}{|l|}{12 ribs with rudimentary } \\
\hline thirteenth rib(s) & 0 & 12 & 2 \\
\hline \multicolumn{4}{|l|}{7 lumbar vertebrae (T13-L1) } \\
\hline \multicolumn{4}{|l|}{12 ribs with thirteenth rib(s) } \\
\hline completely absent & 0 & 5 & 12 \\
\hline \multicolumn{4}{|l|}{7 lumbar vertebrae (T13-L1) } \\
\hline \multicolumn{4}{|l|}{12 ribs with rudimentary } \\
\hline thirteenth rib/s) & 0 & 0 & 6 \\
\hline \multicolumn{4}{|l|}{8 lumbar vertebrae $(\mathrm{T} 13-\mathrm{L} 1 ;+\mathrm{L} 8)$} \\
\hline \multicolumn{3}{|l|}{12 ribs with thirteenth rib/s $)$} & 6 \\
\hline \multicolumn{4}{|l|}{8 lumbar vertebrae $(\mathrm{T} 13-\mathrm{L} 1 ;+\mathrm{L} 8)$} \\
\hline Total & 25 & 54 & 26 \\
\hline \multicolumn{4}{|l|}{ Forelimb malformations } \\
\hline \multicolumn{4}{|l|}{ normal forelimb /carpal bones } \\
\hline not fused $)^{\mathrm{b}}$ & 20 & 34 & 2 \\
\hline partial fusion of carpal bones ${ }^{b}$ & 0 & 7 & 2 \\
\hline complete fusion of carpal bones ${ }^{b}$ & 0 & 10 & 19 \\
\hline Total & 20 & 51 & 23 \\
\hline
\end{tabular}

${ }^{a}$ One $+/+$ skeleton had five lumbar vertebrae.

bPisiform fused to triangular.

mozygous mutants, the T13-to-Ll transformation was complete in nearly all mice, and many of these mutants also showed a second homeotic transformation in the lumbosacral region, with the addition of an eighth lumbar vertebra. Moreover, two homozygous mutants had inappropriate costosternal attachments. Limb defects were also found in Hox A11 mutants, with the pisiform and triangular carpal bones fused, the ulnar epiphysis, ulna and radius misshapen, and abnormal sesamoid development in the forelimb, as well as malformations of the tibia and fibula, and an enlarged sesamoid in the hindlimbs. The homeotic transformations seen in Hox A11 mutant mice support a role for Hox A11 in specifying segment identity during mouse development, and malformations found in the forelimbs and the hindlimbs of mutant mice show directly for the first time that at least one of the expanded set of $A b d-B$ type Hox genes plays a role in limb development.

The observed mutant phenotype in heterozygotes is of particular interest for several reasons. First, heterozygotes for targeted mutations in the four Hox genes examined previously appeared normal (Chisaka and Cappechi 1991; Lufkin et al. 1991; Chisaka et al. 1992; LeMouellic et al. 1992; Ramirez-Solis et al. 1993). This contrasted with the heterozygous mutant phenotypes found for Pax genes (Epstein et al. 1991; Hill et al. 1991), suggesting an inherent functional distinction between the clustered and dispersed Hox genes. The effects in heterozygotes described in this report cast doubt on this conclusion. Second, the observed Hox A11 heterozygote phenotype argues against a simple Hox code hypothesis in which the combinations of Hox genes in the expressed mode directly determine segment identity. The heterozygous effects are likely attributable to reduced levels of Hox A11 transcripts, the result of having only one functional Hox A11 gene. This indicates that Hox expression levels play an important role in specifying segment identity and that the Hox code is assigned by the combination of active Hox genes, and, at least in some cases, by the level of Hox gene expression. Finally, the mutant phenotype observed in Hox A11 heterozygotes is particularly interesting because Drosophila Abd-B heterozygous mutants also show weak homeotic transformations of abdominal segments, reflecting a gene dosage effect (Duncan 1987). This striking parallel adds to the accumulating body of evidence showing surprising functional conservation between the Drosophila and vertebrate Hox genes.

The rule of posterior prevalence states that a Hox gene has its major influence in the domain limited by its anterior boundary and that of the next most $5^{\prime}$ gene in the cluster (Duboule 1991). That is, Hox genes expressed in

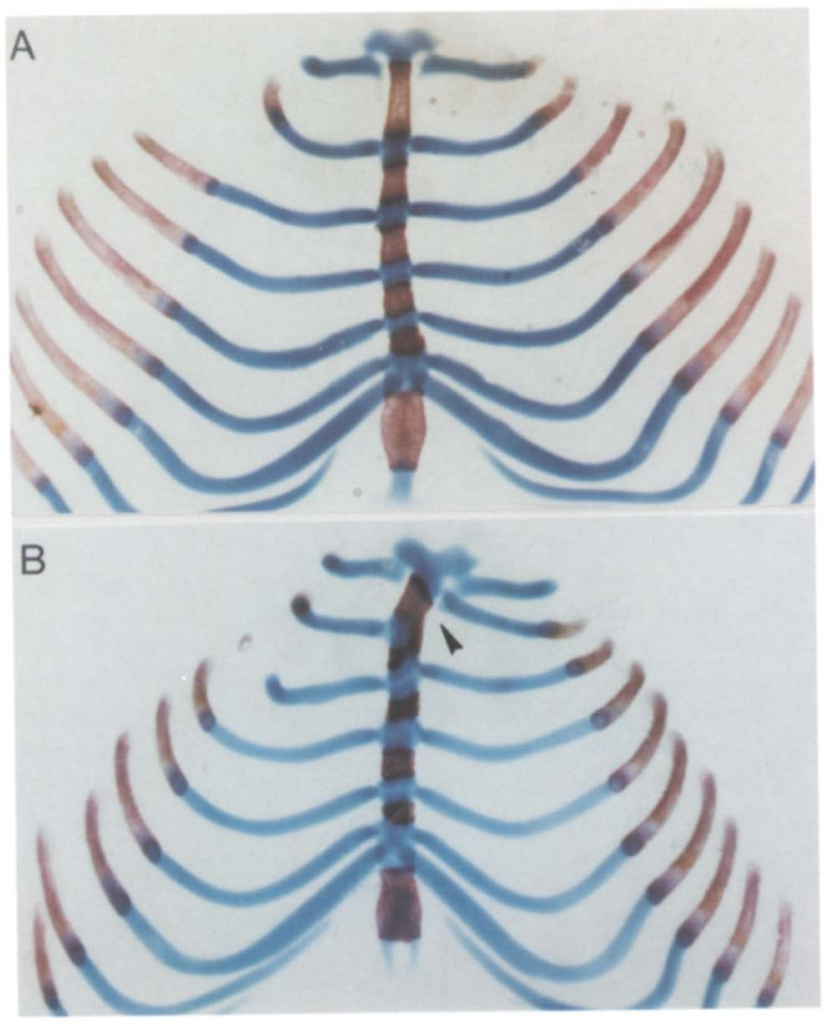

Figure 4. Comparison of ribs from $\operatorname{Hox} A 11+/+$ and $H o x$ A11-/ - mice. The rib cage was dissected away from the thoracic vertebrae. $(A)$ The seven pairs of ribs attached to the sternum in a wild-type mouse. In $B$, the second rib on one side is inappropriately fused to the first rib near the sternum in a mutant mouse (arrowhead). 

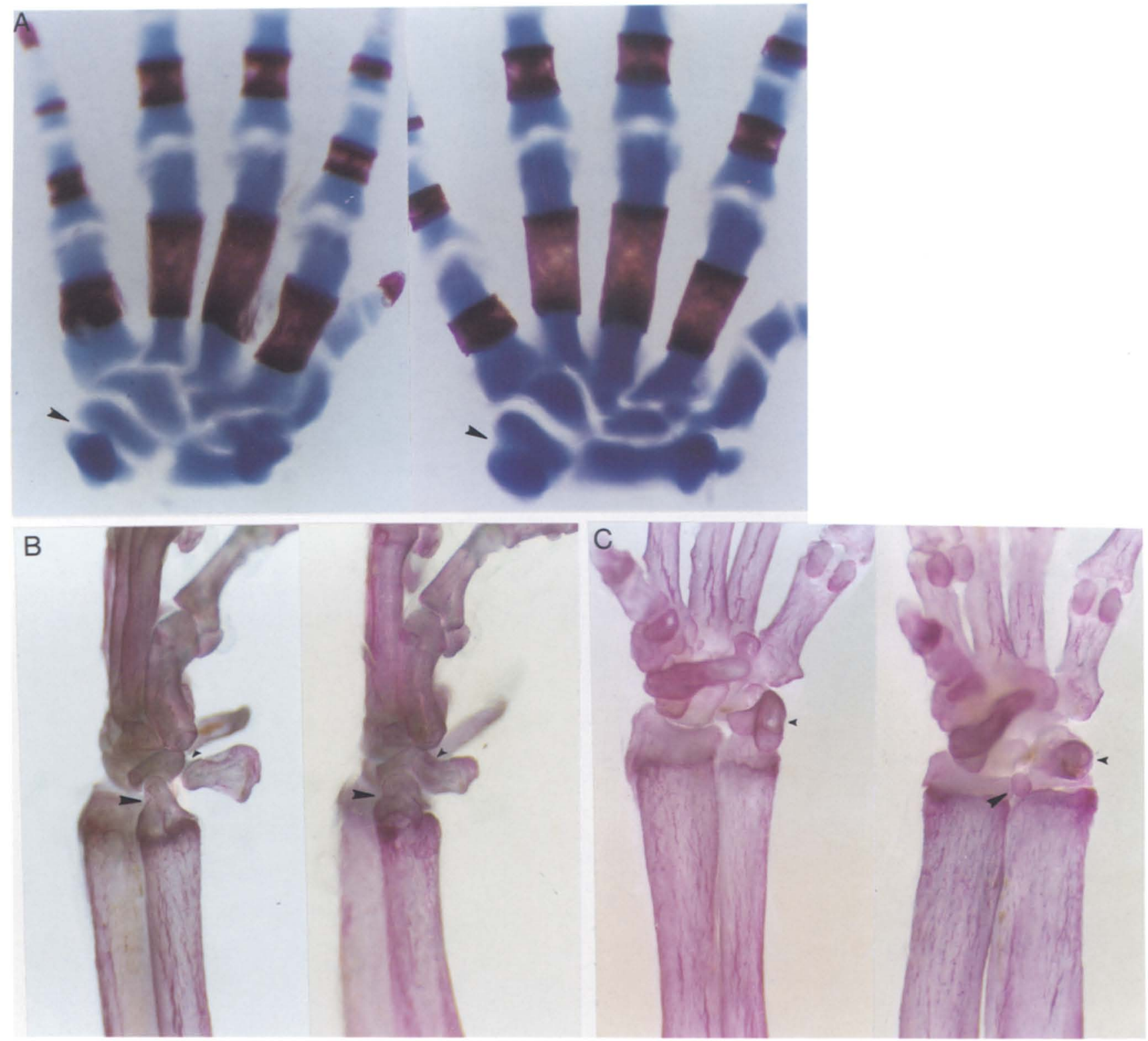

Figure 5. Comparison of forelimbs from Hox $A 11+/+$ and Hox $A 11-/-$ mice. $|A|$ Dorsal view of left forelimbs with the radius and ulna removed shows space between the pisiform and triangular carpal bones in a newborn wild-type mouse (left). These bones are fused in the mutant mouse (right) as indicated by the arrowhead. A side view of the right forelimbs in $B$, with the small arrowheads indicating space between the pisiform and triangular bones in an adult wild-type mouse (left) and fusion of these bones in the mutant (right). The large arrowhead in $B$ points to the misshapen ulnar epiphysis in the mutant. $(C)$ Ventral view of adult left forelimbs from wild-type (left) and mutant (right) mouse shows the large arrowhead pointing to the abnormal sesamoid in the mutant forelimb. This view also shows the misshapen mutant pisiform bone (small arrowhead), and the increased width of the radius and ulna bones.

more posterior domains tend to have dominant effects over Hox genes expressed more anteriorly. As mentioned, the anterior boundary of the Hox $A 11$ axial domain of expression corresponds to prevertebrae 19 (T12) and 20 (T13), (Holland and Hogan 1988). Therefore, the homeotic transformation of $\mathrm{T} 13$ to Ll seen in Hox A11 mutant mice corresponds to this gene's rostral domain of expression and, in this regard, supports the concept of posterior prevalence and resembles phenotypes of other
Hox gene mutants (Chisaka and Cappechi 1991; Lufkin et al. 1991; Chisaka et al. 1992; Ramirez-Solis et al. 1993).

Although the T13-to-L1 transformation occurred where a phenotypic effect of the mutation might be predicted, the observed posteriorization was unexpected. Because Hox genes are expressed with varying rostral boundaries that overlap caudally, ablation of one gene will convert the expressed Hox code for one segment to 

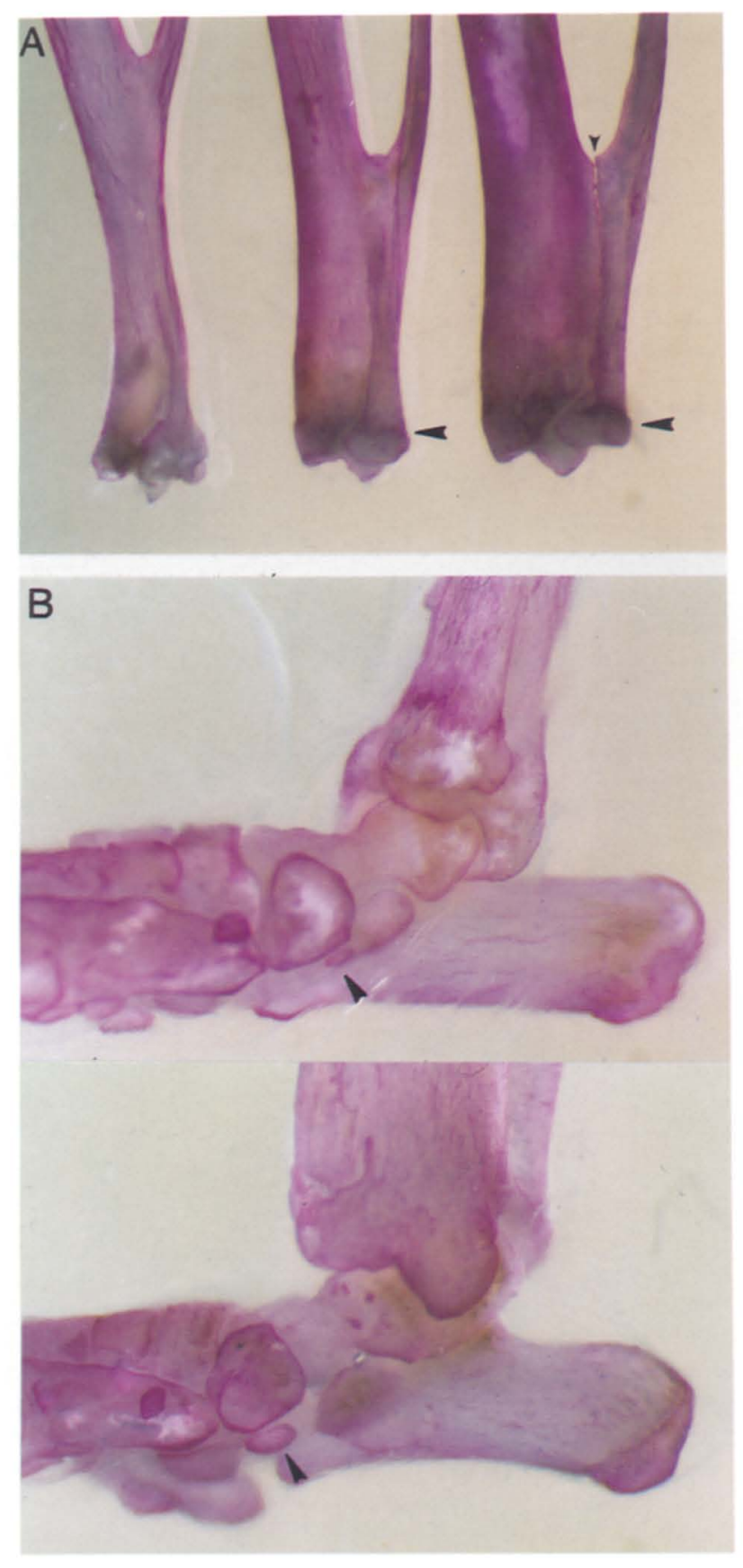

Figure 6. Comparison of hindlimbs from Hox $A 11+/+$, Hox $A 11+/-$, and Hox $A 11-/-$ mice. (A) Dissected tibia and fibula bones from adult wild-type (left), heterozygous (middle), and homozygous (right) mutant mice. In both the heterozygous and homozygous hindlimbs, the fibula and tibia were joined incorrectly at a position distal to that seen in wild-type hindlimbs. In the homozygous mutant hindlimb, the fibula fails to fuse to the tibia, as evidenced by the small gap between the two bones (small arrowhead). In addition, the tibia and fibula appeared wider in mutant hindlimbs, and the distal ends of these bones, the lateral malleolus, and the medial malleolus are malformed (large arrowhead). (B) Side view of wild-type (top) and homozygous mutant (bottom) hindlimbs with the sesamoid bones in dicated by arrowheads. The sesamoid is larger in the mutant hindlimb. the same code normally found one segment anterior (Kessel and Gruss 1991). Hence, one predicts and normally observes anteriorization for Hox gene inactivation and posteriorization for Hox gene misexpression, although exceptions to these generalizations have been described in Drosophila (Kuziora and McGinnis 1988; Gibson et al. 1990).

The observed posteriorization could be the result of misexpression of other Hox genes. It has been shown that ectopic expression of Hox genes in transgenic mice can sometimes cause posteriorization of vertebral segments (Kessel et al. 1990; Lufkin et al. 1992). The disruption of the Hox $A 11$ gene could alter the genetic regulatory network, causing other Hox genes to be expressed inappropriately, indirectly resulting in posteriorization. It is also possible that the insertion of the neo gene has caused misexpression of flanking Hox genes, although in this region of the Hox $A$ cluster, the genes are set apart by $\sim 10 \mathrm{~kb}$ (Haack and Gruss 1993).

The presence of an eighth lumbar vertebra indicates additional homeotic transformations in Hox A11 homozygous mutants. The simplest explanation is an anteriorization of the sacral region by one segment, producing an extra lumbar vertebra. Whereas the transformation at the thoracolumbar boundary altered only one segment, the generation of an additonal lumbar segment at the lumbosacral boundary affected an entire region. At the thoracolumbar border, T12 remained unchanged and T13 was absent in mutants. At the lumbosacral border, an additional lumbar segment was generated without deleting any sacral segment, presumably because each segment in the entire region was anteriorized. Here, as in Hox C8 homozygous mutants described previously, transformations occur within an extended region (LeMouellic et al. 1992). In Hox C8 mutants, homeosis occurred in vertebrae $\mathrm{T} 7-\mathrm{L} 1$, with each vertebra transformed to the identity of the vetebra one segment anterior. Both Hox $A 11$ and Hox C8 transformations show the anteriorization that is predicted for Hox gene null mutants; however, the regions altered do not correspond to the most anterior domains of expression for either gene. Instead, the extended regions are located within the axial domains of expression. Results of this sort demonstrate that posterior prevalence is a tendency rather than a rule.

Incorrect positional information in rib somitic mesoderm appears to have caused misalignment of ribs near the sternum in two homozygous mutant mice. The ribs and sternum originate independently from the somitic region and the lateral mesoderm, respectively (Chen 1952). During normal development, the sternum becomes segmented as a result of inhibition of chondroblastic hypertrophy and subsequent ossification in regions fused to the rib tips (Chen 1953). In mutants, however, incorrect sternal segmentation results when ribs are positioned improperly, causing inappropriate inhibition of ossification on one side of the sternum. This defect is intriguing because it appears outside the observed Hox A11 domain of expression. It is interesting to note that Hox $B 4$ null mutants developed with a split ster- 
num caused by the failure of the sternal rudiments to fuse (Ramirez-Solis et al. 1993). This defect also occurred in a region where Hox $B 4$ transcripts had not been observed. Transient or low levels of Hox A11 and/or Hox $B 4$ expression may not have been detected or, alternatively, the absence of normal inductive interactions may play a role in these mutant malformations.

Hox $A 11$, as well as other $A b d-B$-type Hox genes, is expressed in spatially and temporally restricted domains within the developing limbs. These overlapping domains of gene expression suggest that these genes play important roles during limb morphogenesis. The Hox code hypothesis states that the various combinations of Hox genes active in a particular region of the developing limb will play a role in cell type specification. This model was tested by Morgan et al. (1992), when they used a retroviral vector to misexpress the Hox D11 gene during chick limb development. Interestingly, homeotic transformations of digit identity were observed. Our data indicate that targeted disruption of $H o x$ A11 directly alters the Hox code expressed within the developing limbs. As a result, Hox $A 11$ mutant mice developed abnormal forelimbs and hindlimbs. Mutant forelimbs developed with the fusion of two carpal bones and an abnormal sesamoid. In addition, the radius, the ulna, and the ulnar epiphysis were malformed. Hindlimb development was also effected with improper fusion of the fibula to the tibia and with malformations of the fibula, tibia, lateral malleolus, and medial malleolus. Abnormal sesamoid development was also observed. At E13.5 within the developing limbs, undifferentiated mesenchyme forms precartilaginous condensations, and these condensations later chondrify and ultimately undergo bone replacement. Studies in the chick have shown that individual carpal bones are derived from unique precartilaginous elements (Hinchcliffe 1977). Therefore, improper positional information in Hox A11 mutant mice limbs may have effected development of these precartilaginous elements. Future experiments that examine altered Hox gene expression patterns in mutants and the phenotypic effects of multiple paralogous mutations will further clarify the genetic regulatory network of pattern formation in mammals.

\section{Materials and methods}

\section{Whole-mount in situ hybridization}

The whole-mount hybridization procedure was as described by Rosen and Beddington (1993), except that proteinase K digestion $(10 \mu \mathrm{g} / \mathrm{ml})$ was substituted for the detergent treatment. A segment of $\sim 300$ bp immediately 3 ' of the homeo box was created by PCR, subcloned into pBS (KS, Stratagene), and used to make both sense and antisense riboprobe. Sense probe (not shown) gave occasional weak signals in the otic vesicle and brain ventricles because of antibody trapping.

\section{Construction of the Hox All replacement vector}

A single-copy $0.7-\mathrm{kb}$ HindIII DNA fragment isolated from the original DBA Hox A11 genomic clone (Singh et al. 1991) was used to screen a $129 / \mathrm{Sv}$ genomic library. Two positive clones,
14-10 and 15-8, were used to construct the Hox $A 11$ homologous recombination construct, $p G K O H o x$ A11-129. First a general gene knockout vector, $p G K O V$, was constructed. A $2-\mathrm{kb}$ KpnI herpes simplex virus thymidine kinase (HSV-TK) gene cassette (Mansour et al. 1988) was subcloned into pBS II (SK, Stratagene), and a $2.9-\mathrm{kb}$ Xhol $p G K N e O$ cassette (Soriano et al. 1991) was then blunt end ligated into the BamHI site. In the process, unique restriction enzyme sites, that is, Xhol and NotI, were available to subclone regions of target homology $5^{\prime}$ and $3^{\prime}$ of the neo gene. To make pGKOHox All, a 2.5-kb BamHI-XbaI fragment was subcloned into the NotI site of $p G K O V$ and, a 7.5-kb BamHI-NotI fragment was subcloned into the unique $X$ hol site. The final construct contained $10 \mathrm{~kb}$ of target homology and deleted a $2.5-\mathrm{kb}$ region at the targeted locus, which included the Hox $A 11$ homeo box.

\section{Cell culture and transfections}

D3 ES cells (Doetschman et al. 1985) were maintained on primary G418-resistant mouse embryo fibroblasts in Dulbecco's modified Eagle medium (DMEM) containing 15\% heat-inactivated fetal calf serum, $0.1 \mathrm{~mm} \beta$-mercaptoethanol, $1 \mathrm{~mm}$ sodium pyruvate, $10 \mathrm{~mm}$ penicillin/streptomycin, and $1000 \mathrm{U} / \mathrm{ml}$ of LIF (GIBCO) at $37^{\circ} \mathrm{C}, 5 \% \mathrm{CO}_{2}$. For electroporation, two confluent $100-\mathrm{mm}$ plates of ES cells were trypsinized and resuspended in $3 \mathrm{ml}$ of PBS containing $20 \mu \mathrm{g} / \mathrm{ml}$ of linearized $p$ GKOHox A11129. Three $1-\mathrm{ml}$ aliquots were electroporated at $900 \mathrm{~V}$ and $14 \mu \mathrm{F}$ in a 0.4-cm-wide cuvette (IBI Gene Zapper). Cells were distributed equally on twelve $100-\mathrm{mm}$ plates. G418 at $150 \mu \mathrm{g} / \mathrm{ml}$ was added to the media $24 \mathrm{hr}$ later, and gancyclovir was added $48 \mathrm{hr}$ after electroporation at a final concentration of $2 \mu \mathrm{M}$. Selection was continued for 7 more days. Approximately 300 individual surviving colonies were picked, trypsinized, and passaged to 24-well plates. After 2 or 3 days in culture, one-half of the cells from each well were frozen, and the other half were passaged to gelatin-coated six-well plates. DNA was then prepared for each clone.

\section{DNA analysis}

ES cells were lysed in $0.5 \mathrm{ml}$ of buffer containing $0.2 \mathrm{M} \mathrm{NaCl}, 5$ mM EDTA, $50 \mathrm{~mm}$ Tris- $\mathrm{HCl}(\mathrm{pH} 7.5), 0.2 \%$ SDS, and $20 \mu \mathrm{g} / \mathrm{ml}$ of proteinase $\mathrm{K}$ at $65^{\circ} \mathrm{C}$ for $10 \mathrm{~min}$. Potassium acetate $(200 \mu \mathrm{l})$ was then added, and samples were incubated on ice for at least $1 \mathrm{hr}$. DNA samples were then centrifuged for $20 \mathrm{~min}$ at 12,000 $\mathrm{rpm}$. Ice-cold $100 \%$ ethanol was added to the supernatant, and genomic DNA was spooled out of solution. Mouse tail DNA preps were performed in a similar manner, except the lysis buffer contained $750 \mu \mathrm{g} / \mathrm{ml}$ of proteinase $\mathrm{K}$, and samples were incubated overnight at $65^{\circ} \mathrm{C}$.

Southern blot analysis was performed using GeneScreen Plus as recommended by the membrane manufacturer. DNA probes used for Southern analysis were subcloned, digested, and purified away from vector sequences. To facilitate identification of $+1+,+1-$, and $-1-$ mice, PCR anaylsis was used. Three primers, Neo-5' (TCTGGATTCATCGACTGTGG), H1.9-5' (AATGGCGTACTCTCTGAAGG), and H1.9-3' (TTCCACGTCAGCTTACGT), were used. The resulting PCR products were $\sim 500$ and $300 \mathrm{bp}$ for the heterozygous allele and homozygous alleles, respectively.

\section{Embryo injection and mouse breeding}

C57Bl/6J blastocysts (3.5 days postcoitum) were flushed from the uteri of superovulated 4.5-week-old females with M2 media (Hogan et al. 1986). Approximately 10-15 ES cells were micro- 
injected into the blastocoel of each blastocyst. Injected blastocysts were cultured in a drop of M2 under a layer of paraffin oil at $37^{\circ} \mathrm{C}$ for $1-3 \mathrm{hr}$ and were reimplanted into 2.5-day pseudopregnant CD-1 female mice. Chimeric males were bred to CF-1 females, and germ-line transmission was determined by the presence of agouti offspring in the litter.

\section{Skeletal analysis}

Newborn mice were sacrificed, and their skeletons were stained with alizarin red for bone and alcian blue for cartilage, according to Kuczuk and Scott (1984). Adult limbs were stained with alizarin red only and were heated at $55^{\circ} \mathrm{C}$ for $2-5 \mathrm{hr}$ to facilitate clearing.

\section{Acknowledgments}

We thank M. Schull and T. Doetschman for the $129 / \mathrm{Sv}$ genomic library, T. Ley for the pGKNeo cassette, and D. Collins for photography. This work was supported by a grant (HD 29599) from the National Institutes of Health.

The publication costs of this article were defrayed in part by payment of page charges. This article must therefore be hereby marked "advertisement" in accordance with 18 USC section 1734 solely to indicate this fact.

\section{References}

Awgulewitsch, A. and D. Jacobs. 1992. Deformed autoregulatory element from Drosophila functions in a conserved manner in transgenic mice. Nature 358: 341-344.

Chen, J.M. 1952. Studies on the morphogenesis of the mouse sternum. I. Normal embryonic development. I. Anat. 86: 373-386.

-1953. Studies on the morphogenesis of the mouse sternum. III. Experiments on the closure and segmentation of the sternal bands. J. Anat. 87: 130-149.

Chisaka, O. and M.R. Capecchi. 1991. Regionally restricted developmental defects resulting from targeted disruption of mouse homeobox gene Hox-1.5. Nature 350: 473-479.

Chisaka, O., T.S. Musci, and M. Capecchi. 1992. Developmental defects of the ear, cranial nerves and hindbrain resulting from targeted disruption of the mouse homeobox gene Hox1.6. Nature 355: 516-520.

Doetschman, T.C., H. Elstetter, M. Kate, W. Schmidt, and R. Kemler. 1985. The in vitro development of blastocyst-derived embryonic stem cell lines: Formation of visceral yolk sac, blood islands, and myocardium. J. Embryol. Exp. Morphol. 87: 24-45.

Dolle, P. and D. Duboule. 1989. Two gene members of the murine Hox-5 complex show regional and cell type specific expression in developing limbs and gonads. EMBO I. 8: $1507-1515$.

Dolle, P., J.C. Izpisúa-Belmonte, H. Falkenstein, A. Renucci, and D. Duboule. 1989. Coordinate expression of the murine Hox-5 complex homeobox-containing genes during limb pattern formation. Nature 342: 767-772.

Dolle, P., J.C. Izpisúa-Belmonte, E. Boncinelli, and D. Duboule. 1991. The Hox -4.8 gene is localized at the 5 ' extremity of the Hox 4 complex and is expressed in the most posterior parts of the body during development. Mech. Dev. 36: 3-14.

Duboule, D. 1991. Patterning in the vertebrate limb. Curr. Opin. Genet. Dev. 1: 211-216.

Duncan, I. 1987. The Bithorax Complex. Annu. Rev. Genet. 21: 285-319.
Epstein, D., M. Vekemans, and P. Gros. 1991. Splotch (Sp2H), a mutation affecting development of the mouse neural tube, shows a deletion within the paired homeodomain of $\mathrm{PaX}-3$. Cell 67: 767-774.

Fallon, J.F. and G.M. Crosby. 1977. Polarizing zone activity in limb buds of amniotes. In Vertebrate $\operatorname{limb}$ and somite morphogenesis (ed. D.A. Ede, T.R. Hirschliffe, and M. Balls), pp. 55-69. Cambridge University Press, Cambridge England.

Gehring, W.J. 1987. Homeoboxes in the study of development. Science 236: $1245-1252$.

Gibson, G., A. Schier, L. Motte, and W.J. Gehring. 1990. The specificities of Sex combs reduced and Antennapedia are defined by a distinct portion of each protein that includes the homeodomain. Cell 62: 1087-1103.

Graham A., N. Papalopulu, and R. Krumlauf. 1989. The murine and Drosophila homeobox gene complexes have common features of organization and expression. Cell 57: 367-378.

Haack, H. and Gruss, P. 1993. The establishment of murine Hox-1 expression domains during pattering of the limb. Dev. Biol. 157: 410-422.

Hill, R.E., J. Favor, B. Hogan C. Ton, G. Saunders, I. Hanson, J. Prosser, T. Jordan, N. Hastie, and V. Van Heyningen. 1991. Mouse small eye results from mutations in a paired-like homeobox-containing gene. Nature 354: 522-525.

Hinchliffe, J.R. 1977. The chondrogenic pattern in chick limb morphogenesis: A problem of development and evolution. In Vertebrate limb and somite morphogenesis, pp. 293-309. Cambridge Universtiy Press, Cambridge, England.

Hogan, B., F. Constantini, and E. Lacy. 1986. Manipulating the mouse embryo: A laboratory manual. Cold Spring Harbor Laboratory, Cold Spring Harbor, New York.

Holland, P. and B.M. Hogan. 1988. Spatial patterns of Hox 2.1 gene expression. Development 102: 159-177.

Kaur, S., G. Singh, J. Stock, C. Schreiner, A. Kier, K. Yager, M. Mucenski, W. Scott, and S.S. Potter. 1992. Dominant mutation of the murine Hox-2.2 gene results in developmental abnormalities. J. Exp. Zool. 264: 323-336.

Kessel, M. and P. Gruss. 1991. Homeotic transformations of murine vertebrae and concomitant alteration of Hox codes induced by retinoic acid. Cell 67: 89-104.

Kessel, M. R. Balling, and P. Gruss. 1990. Variations of cervical vertebrae after expression of a Hox-1.1 transgene in mice. Cell 61: 301-308.

Kuczuk, M.H. and W.J. Scott Jr. 1984. Potentiation of acetazolamide induced ectrodactyly in SWV and C57BL/6J mice by cadmium sulfate. Teratology 29: 427-435.

Kuziora, M.A. and W. McGinnis. 1988. Antoregulation of a Drosophila homeotic selector gene. Cell 55: 477-485.

LeMouellic, H., Y. Lallemand, and P. Brulet. 1992. Homeosis in the mouse induced by a null mutation in the Hox 3.1 gene. Cell 69: 251-264.

Lufkin, T., A. Dierich, M. LeMeur, M. Mark, and P. Chambon. 1991. Disruption of the Hox 1.6 homeobox gene results in defects in a region corresponding to its rostral domain of expression. Cell 66: 1105-1119.

Lufkin, T., M. Manuel, C.P. Hart, P. Dolle, M. LeMeur, and P. Chambon. 1992. Homeotic transformation of the occipital bones of the skull by ectopic expression of a homeobox gene. Nature 359: 835-840.

Malicki, J., K. Schughart, and W. McGinnis. 1990. Mouse Hox2.2 specifies thoracic segmental identity in Drosophila embryos and larvae. Cell 63: 961-967.

Malicki, J., L.C. Cianetti, C. Peschle, and W. McGinnis. 1992. A human Hox $4 B$ regulatory element provides head specific expression in Drosophila embryos. Nature 358: 345-347.

Mansour, S.L., K.R. Thomas, and M.R. Capecchi. 1988. Disrup- 
tion of the proto-oncogene int-2 in mouse embryo-derived stem cells: A general strategy for targeting mutations to nonselectable genes. Nature 336: 348-352.

McGinnis, N., M.A. Kuziora, and W. McGinnis. 1990. Human Hox-4.2 and Drosophila deformed encode similar regulary specificities in Drosophila embryos and larvae. Cell 63: 969976.

McLain, K., C. Schreiner, K. Yager, J. Stock, S.S. Potter. 1992. Ectopic expression of Hox-2.3 induces craniofacial and skeletal malformations in transgenic mice. Mech. Dev. 39: 3-16.

Morgan, B.A., J.C. Izpisúa-Belmonte, D. Duboule, and C. Tabin. 1992. Targeted misexpression of Hox-4.6 in the ovian limb bud causes apparent homeotic transformations. Nature 358: 236-239.

Nohno, T., S. Noji, E. Koyama, K. Ohyama, F. Myokai, A. Kuroiwa, T. Saito, and S. Taniguchi. 1991. Involvement of cHox-4 chicken homeobox genes in determination of anteroposterior axial polarity during limb development. Cell 64: 1197-1205.

Peterson, R.L., D.F. Jacobs, and A. Awgulewitsch. 1992. Hox-3.6 isolation and characterization of a new murine homeobox gene located in the $5^{\prime}$ region of the Hox-3 cluster. Mech. Dev. 37: 151-166.

Ramirez-Solis, R., H. Zheng, J. Whiting, R. Krumlauf, and A. Bradley. 1993. Hox B4 (Hox-2.6) mutant mice show homeotic transformation of cervical vertebrae and defects in the closure of sternal rudiments. Cell 73: 279-294.

Rosen, B. and R.S.P. Beddington. 1993. Whole mount in situ hybridization in the mouse embryo: Gene expression in three dimensions. Trends Genet. 9: 162-167.

Scott, M.P. 1992. Vertebrate homeobox gene nomenclature. Cell 71: 551-553.

Singh, G., S. Kaur, J. Stock, N. Jenkins, D. Gilbert, N. Copeland, and S.S. Potter. 1991. Identification of 10 murine homeobox genes. Proc. Natl. Acad. Sci. 88: 10706-10710.

Soriano, P., C. Montgomery, P. Geske, and A. Bradley. 1991. Targeted disruption of the c-src proto-oncogene leads to osteopetrosis in mice. Cell 64: 693-702.

Summerbell, D., J.H. Lewis, and L. Wolpert. 1973. Positional information in chick limb morphogenesis. Nature 244: 492496.

Tickle, C.A., D. Summerbell, and L. Wolpert. 1975. Positional signalling and specification of digits in chick limb morphogenesis. Nature 254: 199-202.

Turing, A.M. 1952. The chemical basis of morphogenesis. Philos. Trans. R. Soc. Lond. (B Biol. Sci.) 237: 37-72.

Welsh, B.J., J. Gomatam, and A.E. Burgess. 1983. Three dimensional chemical waves in the Belousov-Zhabotinski reaction. Nature 304: 611-614.

Yokouchi, Y., H. Sasaki, and A. Kuroiwa. 1991. Homeobox gene expression correlated with the process of limb cartilage development. Nature 353: 443-445. 


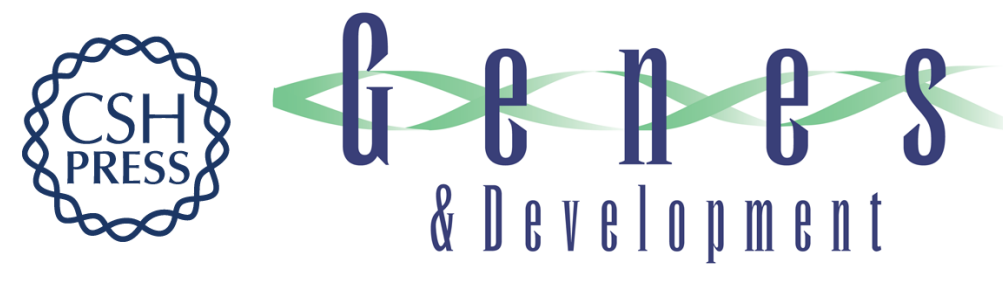

\section{Homeotic transformations and limb defects in Hox A11 mutant mice.}

K M Small and S S Potter

Genes Dev. 1993, 7:

Access the most recent version at doi:10.1101/gad.7.12a.2318

References This article cites 44 articles, 3 of which can be accessed free at:

http://genesdev.cshlp.org/content/7/12a/2318.full.html\#ref-list-1

License

Email Alerting Receive free email alerts when new articles cite this article - sign up in the box at the top Service right corner of the article or click here.

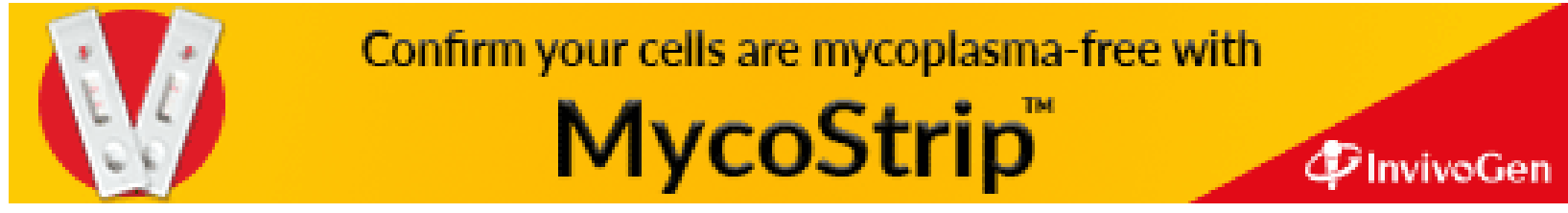

